\title{
BENTUK PENYAJIAN DAN BENTUK MUSIK RAPA'I PASEÉ PADA MASYARAKAT ACEH DI GAMPONG AWE KECAMATAN SYAMTALIRA KABUPATEN ACEH UTARA
}

\author{
Desi Fitriani \\ Prodi Pendidikan Musik
}

\begin{abstract}
This research have purpose ti investigate the existence and the instruments used in Rapa'i Pasee art at Gampong Awe Syamtalira subdistrict Nort Aceh regency. The theory used in this research including the explanation of the existence, the presentation from, explanation meaning of music, music elements, and the organology of music instruments. The population in thi research is music group of Rapa'i Pasee that consist of 16 players, they are 2 was called Syekh (leader), and 14 are music players. The sample in this research is all population that consist 13 persons. The methods used in this research is observation, interviewed, and documentation. The data processing and analysis technic used quality deseriptive research type. The interview result showed Rapa'i Pasee at Gampong Awe Syamtalira subdistrict North Aceh regency now was so interested by people. The Rapa'i Pasee was showed as entertainment in some events, usually like independence day or in prophrt Muhammad Saw birthday or to wecome the country guests. The instruments used is Rapa'i Pasee (like rebana but in big size). The presentation from showed in Rapa'i Pasee played consist 4 chapter (scene), that is Saleum Aneuk Syahi/Cahi, Saleum Aneuk Rakan, Kisah (story) and closing scene. Rapa'i Pasee have own harmony, Rapa'i Pasee have music from one part, two parts nad three parts. Music from one part was sel up in Saleum Rakan and closing scene, two parts in Saleum Aneuk Syahi/Cahi, and three part was set up in Kisah scene.
\end{abstract}

Keywords: Presentation From Rapa'i Pasee, Musical From Rapa’i Pasee 


\section{PENDAHULUAN}

Indonesia adalah sebuah negara yang terdiri atas ribuan pulau yang terbentang dari Sabang sampai Merauke. Indonesia juga sebagai negara yang amat kaya dengan budaya, memiliki musik dengan warna, pola permainan, dan keunikan yang berbeda satu sama lainnya. Keunikan tersebut bisa dilihat dari teknik permainannya, teknik penyajiannya sampai bentuk dan organologi instrumennya. Salah satu daerah yang memiliki musik tradisional yang unik adalah Aceh. Provinsi yang terletak di ujung barat Indonesia ini memiliki kekayaan budaya yang banyak dan khas. Khusus di bidang musik, Aceh memiliki satu alat musik yang hampir seluruh lapisan masyarakatnya mengenal. Meskipun dewasa ini kurang diminati baik orang tua maupun pemudanya.

Masyarakat Aceh memiliki berbagai macam bentuk kesenian, yaitu seni suara, seni tari, seni rupa, seni musik dan seni sastra. Seni suara merupakan suatu bentuk karya seni yang dapat dinikmati manusia melalui pendengaran, seperti seni vokal, dan seni sastra. Seni vokal yang berkembang pada masyarakat Aceh, yaitu peayon aneuk yang berfungsi menidurkan anak, sedangkan seni suara melalui instrument ada yang berupa bunyi atau repertoar musik tradisional yang dimainkan seperti seruné kalé sebagai alat primer yang berperan membawa lagu yang lebih cenderung instrumental, sedangkan Rapa'i adalah alat musik perkusi yang terbuat dari kulit sapi dan kambing berbentuk bulat seperti rebana berukuran besar.

Salah satu musik tradisi Masyarakat Aceh Adalah Rapa'i Pasee, meski dalam kategori alat musik yang tidak terancam punah, untuk Rapa'i Pasee ini nyaris tidak ada lagi pembuatannya. Beberapa kurun waktu belakangan ini para pemuda maupun anak-anak di desa (Gampong) Awe kurang berminat pada musik tradisional apa lagi memainkannya. Bentuk penyajian Rapa'i Pasee ini adalah berbentuk grup, dengan posisi alat musik yang digantung, dan dimainkan dengan cara di tabuh. Keberadaan Rapa'i Pasee ini susah-susah gampang 
menemuinnya mengingat jumlah grup yang sangat sedidkit, sebagian usia pemain musik yang sudah berumur, alat musik yang sudah tua, ditambah jarang sekali ada kesempatan penampilan Rapa'i Pasee. Dan alat musik yang sudah jarang di produksi lagi.

Untuk penampilan Rapa'i Pasee ini pun hanya pada acara tertentu saja dimainkan seperti upacara syukuran politik, menyambut tamu besar pemerintah, upacara maulid, upacara mengenang tragedi-tragedi, upacara membukaan suatu kegiatan, dan lain-lain

Sesuai dengan latar belakang masalah diatas, peneliti sangat tertarik untuk meneliti Bentuk Penyajian Dan Bentuk Musik Rapa'i Pasee Pada Masyarakat Aceh Di Gampong Awe Kecamatan Syamtalira Kabupaten Aceh Utara

Adapun tujuan yang dapat disimpulkan dari latar belakang masalah diatas yaitu:

1. Untuk mengetahui keberadaan musik tradisional Rapa'i Paseé di Gampong Awe Kabupaten Aceh Utara.
2. Untuk mengetahui bentuk penyajian tradisional Rapa'i Paseé di Gampong Awe Kabupaten Aceh Utara.

3. Untuk mengetahui bentuk musik tradisional Rapa'i Paseé di Gampong Awe Kabupaten Aceh Utara.

\section{Bentuk Penyajian}

Sal Murgianto (1983 : 35) menjelaskan bahwa: "ada dua macam bentuk penyajian yang dikenal dengan sebutan representatif dan manifestatif. Bentuk penyajian refresentatif lebih cendrung ke arah realisem, sedangkan manifestatif tidak mengungkapkan masalah secara langsung”. Pengertian penyajian berasal dari kata "saji" yaitu mempersembahkan, sedangkan penyajian itu sendiri mengandung pengertian proses, cara dan perbuatan yang telah tersedia untuk dinikmati. Bentuk penyajian dalam musik adalah suatu susunan atau wujud penyajian musik secara utuh.

\section{Musik}

Menurut Soeharto (2001: 86) musik adalah seni mengungkapkan gagasan melalui suara atau bunyi yang unsur dasarnya berupa irama, 
harmoni, dengan unsur pendukung berupa gagasan, sifat, dan warna bunyi. Namun berikut beberapa unsur-unsur musik

\section{Rapa'i Pasee}

Rapai merupakan sejenis alat instrumen musik tradisional Aceh, sama halnya dengan gendang. Rapai dibuat dari kayu yang keras (biasanya dari batang nangka) yang setelah dibulatkan lalu diberi lobang di tengahnya. Kayu yang telah diberi lubang ini disebut baloh. Baloh ini lebih besar bagian atas dari pada bagian bawah. Bagian atas ditutup dengan kulit lembu sedangkan bawahnya dibiarkan terbuka. Penjepit kulit atau pengatur tegangan kulit dibuat dari rotan yang dibalut dengan kulit (penjepit ini dalam bahasa Aceh disebut sidak). Rapai digunakan sebagai alat musik pukul pada upacara-upacara terutama yang berhubungan dengan keagamaan, perkawinan, kelahiran dan permainan tradisional yaitu debus. Memainkan rapai dengan cara memukulnya dengan tangan dan biasanya dimainkan oleh kelompok (grup). Pemimpin permainan rapai disebut syeh atau kalifah.

\section{METODE PENELITIAN}

Maryeni (2005:1) yang mengatakan bahwa : penelitian (research) merupakan usaha memahami fakta secara rasional; yang ditempuh melalui prosedur kegiatan tertentu sesuai dengan cara yang ditentukan oleh peneliti. Dalam konteks penelitian istilah "fakta" memiliki pengertian tidak sama kenyataan, tetapi lebih mengacu pada sesuatu tersebut berbentuk kesadaran seseorang terhadap sesuatu yang dipikirkan. Sesuatu yang berbentuk dalam pikiran seseorang tersebut belum tentu secara konkret, dapat dilihat dan ditemukan dalam kenyataann yang sebenarnya.

\section{Lokasi dan Waktu penelitian}

Sesuai dengan judul penelitian "Bentuk Penyajian dan Bentuk Musik Rapa'i Paseé Pada Masyarakat Aceh di Gampong Awe Kecamatan Syamtalira Kabupaten Aceh Utara", penelitian ini dilaksanakan di Gampong Awe Kecamatan Syamtalira Kabupaten Aceh Utara dan waktu penelitian dilakukan pada bulan Februari-April 2015. 


\section{Polulasi Dan Sampel}

\section{Polulasi}

Populasi merupakan jumlah total elemen dalam penelitian dan merupakan hal yang penting untuk menentukan jumlah populasi sesuai dengan data yang akan dikumpulkan, maka yang menjadi populasi dalam penelitian ini adalah kelompok Rapa'i Pasee yang mempunyai berjumlah tujuh belas (17) orang, yang terdiri dari enam belas (16) orang pemain musik, satu orang ketua kelompok Rapa'i Pasee yang bernama Hasbullah yang sekaligus menjadi narasumber dalam penelitian ini

\section{Sampel}

Yang menjadi sampel dalam penelitian adalah keseluruhan dari populasi yang berjumlah tujuh belas (17) orang, enam belas (16) pemain musik, satu ketua kelompok.

\section{Teknik Pengumpulan Data}

Teknik pengumpulan data yang dilaksanakan adalah sebagai berikut.

1. Pengamatan/Observasi

2. Wawancara

3. Studi Kepustakaan

4. Dokumentasi

\section{Teknik Analisis Data}

Semua data yang diperoleh dari lapangan dicatat kemudian diolah dan di analisis dengan teliti. Hasil olahan dan analisis tersebut sebagai bahan tulisan agar nantinya ditemukan tema yang akan dirumuskan, dan dari hasil rumusan tersebut mungkin dapat suatu teori baru.

Untuk menganalisis data yang telah diperoleh dalam penelitian ini, nantinya akan dianalisis dengan menggunakan teknik deskriptif kualitatif yaitu teknik menguraikan permasalahan secara sistematis dan teliti apa adanya dengan menggunakan uraian dan bukan dalam bentuk angkaangka. Selanjutnya, hasil pengolahan data analisis tersebut disusun secara sistematis dengan tehnik deskriptif kualitatif, sehingga hasil dapat dilihat didalam betuk laporan ilmiah atau skripsi.

Keberadan Rapa'i Pasee Di

\section{Gampong Awe}

Rapa'i merupakan salah satu bentuk Musik Tradisional Aceh, ia hidup dan berkembang sesuai dengan kebutuhan masyarakat 
pendukungnya. Sampai sekarang keberadaan Rapa'i masi tetap disenangi dan diminati oleh Masyarakat Aceh sebagai salah satu bentuk kesenian tradisional baik dalam konteks adat istiadat maupun agama islam

Keberadaan Rapa'i Pasee di Gampong Awe masih untuh ada, yang biasanya dipakai untuk acara hiburan, namun meski Rapa'i Pasee sudah terkenal luas untuk meneruskan para Awak Rapa'i Pasee ini sangat susah dikarenakan para pemain Rapa'i Pasee ini orang tua saya atau yang sudah menikah. Rapa'i Pasee di Gampong Awe ini biasanya dimainkan pada acara kebesaran seperti acara Maulid Nabi Muhammad, Pesta perkawinan, Menyambut tamu Provinsi atau tamu Negara. Dan lain-lain.

\section{Bentuk Penyajian Rapa'i Pasee}

Rapa'i Paseé tidak dimainkan oleh lelaki perjaka atau belum menikah. Ini bukanlah syarat, melainkan pemuda di daerah tersebut tidak memilih Rapa'i Paseé sebagai pilihan, melainkan Rapa' $i$ biasa yang lebih ringan dan kecil. Masyarakat setempat yang memainkan Rapa'i
Paseé biasanya adalah laki-laki dewasa yang telah menikah. Sekali lagi ini bukan syarat, hanya saja seperti konvensi yang kemudian menjadi tradisi. Sehingga kemudian Rapa'i Paseé sering disebut Rapa'i Tuha (Rapa'i tua) karena dimainkan oleh "orang tua".

Cara memainkannya adalah dengan ditepuk pada bagian atas atau bagian kulit. Rapa'i Paseé tidak dinyanyikan dengan mulut hanya instrumen saja. Kalau dapat dikatakan pukulan adalah lagu, lagu adalah pukulan. Untuk notasi, nada, ritme pukulan sejauh ini tidak ada perubahan. Tidak banyak format pukulan yang diciptakan. Bahkan untuk notasi baru dapat dikatakan tidak ada. Dalam sekali main, Rapa' $i$ Paseé minimal satu jam, maksimal 6-7 jam. Satu tim terdiri minimal 1530 pemain.

\section{Bentuk Musik}

Bentuk dan bahasa mempunyai kesamaan fungsi yaitu sebagai media komunikasi. Proses terbentuknya sebuah komposisi musik dapat disejajarkan dengan proses terbentuknya komposisi dalam bahasa. Kata dirangkai 
menjadi frase; frase dirangkai menjadi kalimat; dan seterusnya. Dalam komposisi musik biasanya sebuah kalimat atau periode terdiri atas anak kalimat atau frase; frase terdiri atas motif. Motif adalah satuan bentuk musik terkecil yang mengandung arti musikal.

Bedasarkan penelitian dan wawancara yang dilakukan dengan Hasbullah (1 Maret 2015), diperoleh gambaran tentang pola ritme dasar, yakni sebagai pola ritme yang memiliki karakter kuat dalam permainan Rapa'i Pasee. Pola ritme dasar dalam permainan Rapa'i Pasee terdapat pada tabuhan-tabuhan yang dimainkan oleh para Awak Rapa'i Pasee. Dalam Rapa'i Pasee hanya memiliki bentuk lagu satu bagian yang hanya terdiri dari satu kalimat saja dan diikuti oleh pengulangan (A, A'). Seperti pasa Saleum Aneuk Syahi/cahi memiliki bentuk musik satu bagian (A, $\left.\mathbf{A}^{\prime}\right)$, Saleum Aneuk Rakan memiliki bentuk meusik satu bagian (A, A'), Kisah memiliki bentuk musik satu bagian (A, A') dan Penutup juga memiliki bentuk musik satu bagian (A, $\left.\mathbf{A}^{\prime}\right)$.

\section{PENUTUP}

Berdasarkan data yang telah diperoleh langsung ditempat penelitian, maka dapat dibuat kesimpulan sebagai berikut :

1. Keberadaan Rapa'i Paseé hanya terdapat di Aceh Utara, sampai saat ini Rapa'i Pasee ini masih dimainkan, namun yang memainkannya hanya orang dewasa yang sudah menikah, makanya Rapa'i Pasee ini juga sering disebut Rapa'i Tuha (Rapa'i Tua), namun pemain atau pelakon Rapa'i Paseé memiliki jumlah terbanyak mencapai minimal 15 dan maksimal 30 orang dalam satu kali tampil. Cara memainkannya di pukul (ditampar, ditabuh) dengan telapak tangan.

2. Bentuk penyajian Rapa'i Paseé ini di laksanakan dengan empat babak yaitu 1) Saleum Aneuk Syahi/Cahi, 2) Saleum Aneuk Rakan, 3) Kisah, dan 4) Penutop.Saat dimainkan Rapa'i Paseé akan digantung, karena bobotnya yang memiliki berat yang 
tidak mampu dipikul.

Sehingga permainan Rapa'i

Paseé dilakukan dalam

keadaan berdiri (rata-rata)

dan setengah berdiri

(jongkok) disesuaikan

formasi. Rapa'i Paseé ini

adalah Rapa'i tertua di

seluruh Aceh, yang

merupakan cikal bakal

lahirnya Rapa'i - Rapa'i

lainnya di Aceh.

3. Bentuk musik tradisionalnya terletak pada ritem yang memilikii bentuk kalimat yang berbeda-beda, frase yang berbeda-beda dan motif yang berbeda-beda pula.

\section{A. Saran}

Dari beberapa kesimpulan di atas, peneliti mengajukan beberapa saran, antara lain :

1. Bagi penelitian selanjutnya dapat mencoba membedah syair yang terdapat dalam Rapa'i Paseé, makna dan bentuknya.

2. Bagi pembaca diharapkan dapat menemukan social history (sejarah sosial) dan amanat dari keberadaan Rapa'i Paseé hari ini. Meningkatkan eksistensi sebuah karya seni besar yang lahir langsung dari masyarakat pemiliknya tanpa terkontaminasi zaman.

3. Bagi masyarakat tempat karya itu lahir (masyarakat Aceh); agar senantiasa

mempertahankan karya seni besar ini agar terus hidup dan memliki eksistensi (keberadaan) yang jelas. Terutama generasi penerus estafet pelaku Rapa'i Paseé.

4. Bagi pemerintah Kebupaten Aceh Utara dan Aceh umumnya untuk dapat memberi perhatian khusus bagi seni dan pelakunya. Dalam hal ini kesenian Rapa'i Paseé dan pemainnya 


\section{DAFTAR PUSTAKA}

Arikunto, Suharsimi. 2006, Prosedur Penelitian, Jakarta: PT Rineka Cipta.

Azari, Azril. 2001. "Bentuk dan Gaya Penulisan Karya Tulis Ilmiah". Cetakan ke IV. Universitas Trisakti ; Jakarta

Budilinggono, I. 1993. Bentuk dan AnalisisMusik.

Jakarta:Direktur Jendral

Pendidikan Dasar dan

Menengah Departemen

Pendidikan dan Kebudayaan.

Hardjana, suka. 2003. Corat - Coret Musik Kontemporer Dulu dan Kini. Jakarta: Ford Foundantion.

Ishak, dkk. 1978/1979. Esklopedia Musik dan Tari Daerah Propinsi Daerah Istimewa Aceh, Banda Aceh : Depdikbud.

Irwansyah. 2010. Peranan dan Bentuk Musik Pada Pertunjukan Debus di Aceh.
Skripsi FBS. Universitas Negeri Medan.

Lestari, Syera Fauzya. 2013. Konsep Koreografi Tari Rapa'i Geleng Inong Pada Masyarakat Aceh Utara. Skripsi FBS. Universitas negeri Medan.

Manalu, Vinsensia Ningsih. 2009. Bentuk Penyajian Makna Simbolik dan Nilai Estetika Tari Persembahan Pemulya Jameé Pada Upacara Perkawinan Masyarakat Langsa. Skripsi FBS. Universitas Negeri Medan.

Margono. 2009. Metode Penelitian Pendidikan. Jakarta : Pustaka Umum

Maryeni. 2005. Metode Penelitian Kebudayaan". Jakarta ; Bumi Aksara

Miles, B. Matthew dan Suberman, A. Michael, 2005. Analisis Data Kualitatif. Jakarta: UIPRESS. 
Murgianto, Sal. 1983. Penyajian

Dalam Sebuah Pertunjukan.

Bogor : Mutiara

Narbuko, Achmadi. 2005. "Metode Penelitian”. Cetakan ke VII, Jakarta ; Bumi Aksara

Soeharto. 2001. Musik Dalam Mencerdaskan Anak. Jakarta : Cakrawala.

Sugiyono. 2008. Metode Penelitian Kuantitatif Kualitatif. Bandung : Alfabeta.

Supranto, J. 2004. "Proposal Penelitian dan Contoh". Cetakan Pertama. Jakarta Universitas Indonesia (UIPRESS).

Sukmadinata, Nana Syaodih 2008. "Metode Pendidikan". Remeka Kosda Karya: Bandung.

Syahputra, Awal Ahmad. 2012. Fungsi Teknik Permainan Instrumens Dan Bentuk Penyajian Musik Tradisional Gondang Hasapi Keluarga
Seni Batak Japaris Bagi Masyarakat Batak Toba Di Yogyakarta. Skripsi FBS. Universitas Negeri Yogyakarta

Tampubolon. 2007. Teori Musik. Bogor : Piranti Darma.

Yuliana. 2006. Bentuk Penyajian Rapa'i Liepek Di Desa Pante Pieyeu Kecematan Peusangan Kabupaten Bireuen. Skripsi FKIP. Universitas Syiah Kuala 